\title{
Multiple micronutrients in powder delivered through primary health care reduce iron and vitamin A deficiencies in young Amazonian children
}

\author{
Cristieli SM Oliveira ${ }^{1,2}$, Patrícia Sampaio², Pascoal T Muniz ${ }^{2}$ and Marly A Cardoso 1,3,* \\ for the ENFAC Working Group \\ 'Public Health Nutrition Program, School of Public Health, University of São Paulo, São Paulo, Brazil: ${ }^{2}$ Centre of \\ Health Sciences and Sport, Federal University of Acre, Rio Branco, Brazil: ${ }^{3}$ Department of Nutrition, School of Public \\ Health, University of São Paulo, Avenida Dr. Arnaldo 715, São Paulo, SP 01246-904, Brazil
}

Submitted 14 March 2016: Final revision received 18 April 2016: Accepted 25 April 2016: First published online 30 May 2016

\begin{abstract}
Objective: We evaluated the effect of home fortification with multiple micronutrient powder (MNP) on anaemia and micronutrient status of young Amazonian children.

Design: A pragmatic controlled trial was performed. A control group (CG) of children aged 11-14 months was recruited in the routine of primary health-care centres for assessing anaemia and micronutrient status. At the same time, an intervention group (IG) of infants aged 6-8 months was recruited in the same health centres to receive MNP daily in complementary feeding for 2 months. The IG children were assessed 4-6 months after enrolment ( $n$ 112) when they had reached the age of the CG participants ( $n$ 128) for comparisons.

Setting: Primary health centres in Rio Branco city, Brazilian Amazon.

Subjects: A total of 240 children aged $<2$ years.

Results: In the CG, the prevalence of anaemia ( $\mathrm{Hb}<110 \mathrm{~g} / \mathrm{l})$, iron deficiency (ID; plasma ferritin $<12 \mu \mathrm{g} / \mathrm{l}$ or soluble transferrin receptor $>8.3 \mathrm{mg} / \mathrm{l}$ ) and vitamin A deficiency (VAD; serum retinol $<0.70 \mu \mathrm{mol} / \mathrm{l}$ ) was $20.3 \%, 72.4 \%$ and $18.6 \%$, respectively. Among the IG participants (aged 11-14 months), the prevalence of anaemia, ID and VAD was $15.2 \%, 25.2 \%$ and $4.7 \%$, respectively. The IG had a lower likelihood of ID (prevalence ratio (95\% CI): $0.34(0 \cdot 24,0 \cdot 49))$ and VAD $(0 \cdot 25(0 \cdot 09,0 \cdot 64))$.

Conclusions: Home fortification of complementary feeding delivered through primary health care was effective in reducing iron and vitamin A deficiencies among young Amazonian children.
\end{abstract}

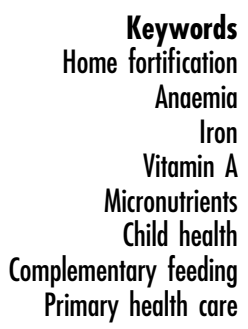

Anaemia remains an ongoing challenge worldwide, with important adverse effects on child survival and development $^{(1)}$. Globally, it was estimated that 273 million children of pre-school age were anaemic in $2011^{(2)}$ and that 190 million were vitamin A-deficient in $2009^{(3)}$. Iron deficiency (ID) is widespread and accounts for approximately one-half of anaemia cases in children worldwide ${ }^{(4)}$. Most of these affected populations are in developing countries, where anaemia often coexists with other micronutrient deficiencies ${ }^{(5)}$

Dietary inadequacies with insufficient nutrient intake and limited nutritional diversity during the first 2 years of life are major determinants of anaemia and micronutrient deficiencies in young children ${ }^{(6)}$. Anaemia may be caused

$\dagger$ See Appendix for the full list of members of the ENFAC Working Group. by many other factors, including infections, inadequate care, essential micronutrient deficiencies (vitamin A, folic acid and vitamin $\mathrm{B}_{12}$ ), exposure to an unhealthy environment and adverse socio-economic conditions ${ }^{(1)}$.

Micronutrient deficiencies have a significant impact on individuals, including increased morbidity and impaired physical growth, cognitive development and school performance $^{(1)}$. Micronutrient deficiencies also adversely affect societies, resulting in poorer health, lower educational attainment and decreased physical work capacity and productivity, with deleterious consequences on economic development and human capital ${ }^{(7)}$.

Brazil has a set of control and prevention strategies for anaemia ranging from mandatory fortification of flour to Fe supplementation of at-risk groups. Fe supplementation, although considered an effective strategy, has poor 
adherence because of the adverse effects of ferrous sulfate $^{(8)}$. Fortification of wheat and corn flour with folic acid and $\mathrm{Fe}$ has demonstrated low effectiveness in preventing childhood anaemia among young children ${ }^{(9)}$. Anaemia remains a public health problem in children across the country, with a prevalence as high as $40 \%$ among children under 2 years of age in some locations, such as the Brazilian Amazon ${ }^{(10)}$.

Since 2011, home fortification with multiple micronutrient powder (MNP) has been recommended as an alternative strategy for controlling anaemia and micronutrient deficiency among children 6 to 23 months of age in locations where prevalence is $20 \%$ or higher ${ }^{(11)}$. Home fortification with MNP combined with educational intervention to promote improved feeding practices for young children is considered an effective strategy for reducing anaemia and ID among children, most notably in low-income countries $^{(12)}$. For other health outcomes such as linear growth $^{(13)}$ and vitamin A deficiency (VAD), the use of home fortification with MNP has shown positive effects, although results remain inconclusive ${ }^{(13,14)}$. However, some studies have found that this approach results in an unsatisfactory incidence of diarrhoea as a side-effect ${ }^{(14,15)}$.

The present study aimed to evaluate the effectiveness of home fortification of complementary feeding with MNP delivered through the primary health-care units of the National Unified Health System on Hb concentration and the prevalence of anaemia, ID, VAD and other vitamin deficiencies among young Brazilian Amazonian children.

\section{Methods}

\section{Study area, design and participants}

The present study is part of Estudo Nacional de Fortificação caseira da Alimentação Complementar (ENFAC), a multicentre pragmatic controlled clinical trial carried out in Brazil. Study design details and fieldwork procedures have been previously reported ${ }^{(16)}$. The ENFAC study was designed to assess the impact of MNP on anaemia in young children attending primary health-care clinics in four Brazilian cities (Rio Branco, Goiânia, Olinda and Porto Alegre). For the present analysis, data from Rio Branco were examined to explore the effect of MNP in a region with high social vulnerability. Rio Branco is the capital of the state of Acre, located in the western Brazilian Amazon. In 2010, Rio Branco had a total population of 336038 people. Of these, $9 \%$ were children younger than 4 years of age. Infant mortality in Rio Branco, estimated at 20 per 1000 live births in 2010, is higher than the Brazilian average (16.7 per 1000 live births) ${ }^{(17)}$. Primary health-care coverage under the Family Health Program is low in this state $(38 \cdot 7 \%)^{(18)}$.

The study was conducted at six primary health-care units between June 2012 and February 2013. At baseline, the mothers or guardians of children aged 11-14 months receiving routine paediatric care were invited to participate in the study as the control group (CG). At the same time, an intervention group (IG) of infants aged 6-8 months was recruited through the same health centres to receive home fortification with MNP given once daily in their usual food over a period of $60 \mathrm{~d}$, as per WHO guidelines $^{(11)}$. Because of ethical restrictions on collecting blood samples from 6- to 8-month-old infants, we did not collect blood samples from IG participants prior to the intervention. Therefore, the comparison between the two groups was performed when the children in the IG reached the age of the CG children at enrolment.

The eligibility criteria for participation were as follows: (i) parental approval to participate in the study; and (ii) not currently receiving treatment for anaemia as reported by caregivers. Exclusion criteria: included premature birth (<37 weeks' gestation); twins; reported cases of HIV infection, malaria, tuberculosis or haemoglobinopathies; and fever $\left(>39^{\circ} \mathrm{C}\right)$ on the day of blood sampling.

A required sample size of at least 105 children in each study group was estimated to detect an increase in mean $\mathrm{Hb}$ of $6 \mathrm{~g} / \mathrm{l}$ with a power of 0.95 and a two-tailed $\alpha$ level of $0 \cdot 05^{(19)}$. The sample size was increased to 135 to account for loss to follow-up in the IG.

\section{Intervention}

The MNP supplement used in this study was MixMe ${ }^{\mathrm{TM}}$, manufactured by DSM Nutritional Products Europe, Ltd and donated by UNICEF. Each sachet contained fifteen vitamins and minerals, including: $10 \mathrm{mg} F$ (encapsulated ferrous fumarate), $4.1 \mathrm{mg} \mathrm{Zn}$ (zinc gluconate), $150 \mu \mathrm{g}$ folic acid, $400 \mu \mathrm{g}$ vitamin A (retinol equivalents), $30 \mathrm{mg}$ vitamin C (ascorbic acid), $5 \mu \mathrm{g}$ cholecalciferol, $5 \mathrm{mg}$ vitamin $\mathrm{E}$ (tocopherol equivalents), $0.5 \mathrm{mg}$ thiamin, $0.5 \mathrm{mg}$ riboflavin, $0.5 \mathrm{mg}$ vitamin $\mathrm{B}_{6}, 0.9 \mu \mathrm{g}$ vitamin $\mathrm{B}_{12}, 6 \mathrm{mg}$ niacin, $0.56 \mathrm{mg} \mathrm{Cu}, 90 \mu \mathrm{g}$ iodine and $17 \mu \mathrm{g}$ Se.

First, health-care workers were invited to a $1 \mathrm{~h}$ learning session provided by the research team before MNP distribution. As previously described ${ }^{(16)}$, the research team provided technical assistance to health-care workers, with written materials to assist development of the MNP intervention and to integrate it with the existing health-care programme. Caregivers were instructed by health-care professionals to mix the contents of one MNP sachet with semi-solid food daily just before serving. They were provided with a 2-month supply with a flexible scheme (60 sachets per child). Adherence was estimated based on quantity of sachets consumed, using data on sachets remaining at home at the end of the trial. Acceptability was assessed with an interview at the end of the trial to assess perceptions of mothers toward MNP (such as side-effects, children's acceptance of food mixed with MNP, type of food used and overall acceptability).

\section{Data collection and biochemical analysis}

The CG was enrolled at 11-14 months of age. At baseline, trained fieldworkers performed structured face-to-face interviews with each child's mother or guardian at the 
routine health-care centre or during household visits through active search in the territory covered by the primary health units. Interviewers were trained prior to conducting the survey. Additional interviews either by telephone or at home visits were conducted if missing values were identified during the data collection and cleaning stage. The following information was collected: demographic characteristics (child's sex, age and race/ ethnicity); socio-economic status (parental education, maternal occupation, number of residents in the household) and access to public services (treated water, garbage collection, type of basic health-care unit); reproductive health variables (maternal age, number of antenatal appointments, birth weight retrieved from child's health record); infant feeding practices (child's age at introduction of weaning foods) and morbidity (diarrhoea, wheezing, cough or fever in the $15 \mathrm{~d}$ prior the interview). Infant length was measured by trained research assistants according to standardized procedures ${ }^{(20)}$ using portable infant measuring boards (model ES-2000; Sanny, Los Angeles, CA, USA). Each measurement was repeated and the mean value calculated. $Z$-scores for length/heightfor-age (HAZ) were calculated according to the WHO child growth standards ${ }^{(21)}$. Stunting was defined as HAZ $<-2 \cdot 0^{(20)}$.

The IG infants were enrolled at 6-8 months of age to receive the intervention. Four to six months after enrolment, when the children in the IG reached the age of the CG children at enrolment, research interviewers performed the same data collection procedures as described above for the CG children, with additional questions about MNP consumption and a count of leftover sachets at the end of the trial. Common semi-solid food used for consumption of the sachet was also asked.

\section{Biochemical analysis}

A sample of fasting ( $\geq 3 \mathrm{~h}$ ) venous blood was collected in the morning on a day scheduled with caregivers (at enrolment for the CG and 4-6 months after enrolment for the IG children). At the laboratory, whole blood aliquots collected in EDTA-containing vacuum tubes were used to measure $\mathrm{Hb}$ concentrations on portable haemoglobinometers (Hb301; HemoCue ${ }^{\circledR}$, Angelholm, Sweden) by trained nurses following recommended standardization procedures ${ }^{(22)}$. A separate blood sample was protected from light and centrifuged within $1 \mathrm{~h}$ of collection; serum and plasma samples were frozen at $-20^{\circ} \mathrm{C}$ before being shipped to São Paulo on dry ice and maintained at $-70^{\circ} \mathrm{C}$ until further analysis. In São Paulo, plasma ferritin and soluble transferrin receptor concentrations were measured with commercially available enzyme immunoassays (Ramco, Houston, TX, USA). C-reactive protein $>5 \mathrm{mg} / 1$ and $\alpha_{1}$-acid glycoprotein $>1 \mathrm{~g} / \mathrm{l}$ were defined as acute and chronic inflammation ${ }^{(23)}$, respectively, and were measured with the IMMAGE Immunochemistry System (Beckman Coulter, Brea, CA, USA).
Anaemia, ID and iron-deficiency anaemia (IDA) were defined according to $\mathrm{Hb}$, plasma ferritin and soluble transferrin receptor as follows: anaemia was defined as $\mathrm{Hb}<110 \mathrm{~g} / \mathrm{l}$; ID was defined as plasma ferritin $<12 \mu \mathrm{g} / \mathrm{l}$ or soluble transferrin receptor $>8.3 \mathrm{mg} / \mathrm{l}$; IDA was defined as ID occurring in anaemic children. Serum folate and vitamin $\mathrm{B}_{12}$ concentrations were measured using commercial fluoroimmunoassays (Perkin Elmer, Wallac Oy, Turku, Finland). Folate deficiency was defined as serum folate $<10 \mathrm{nmol} / \mathrm{l}$ and vitamin B12 deficiency as serum vitamin B12 <150 pmol/ $\mathrm{l}^{(24)}$.

Serum concentrations of $\beta$-carotene, retinol and vitamin E were measured with HPLC methods (HP-1100 HPLC system; Hewlett Packard, Palo Alto, CA, USA) as previously described ${ }^{(25)}$. Serum retinol concentration $<1.05 \mu \mathrm{mol} / 1$ and $<0.70 \mu \mathrm{mol} / 1$ was used to indicate vitamin A insufficiency and VAD, respectively ${ }^{(24)}$. Vitamin E insufficiency was defined as serum vitamin E level $<11.6 \mathrm{mmol} / 1$. Frozen samples were analysed within 6 months of collection. Laboratory results were provided to the caregivers or community health workers for further follow-up and treatment when necessary.

\section{Statistical analysis}

We used an intent-to-treat analysis; i.e. we compared main outcomes in the IG with those in the CG, regardless of adherence to intervention. The primary outcome measure was the difference in mean $\mathrm{Hb}$. Secondary outcome measures were the prevalence of anaemia, ID, VAD and other vitamin deficiencies and mean HAZ. Median values and interquartile ranges were calculated for micronutrient concentrations and continuous covariates according to outcome status. Pearson's $\chi^{2}$ test was used to examine differences in proportions and Student's $t$ test or the Mann-Whitney $U$ test was used to evaluate differences in continuous variables between groups. We used Poisson regression models with robust variance to estimate values for the prevalence ratios with 95\% confidence intervals for the outcome variables. Differences were considered significant at $P<0 \cdot 05$. All $P$ values were derived from two-sided statistical tests. We used the statistical software package STATA $13 \cdot 0$ for all analyses.

\section{Results}

Figure 1 shows the flowchart of participant recruitment and selection for the present study. A total of 326 children were eligible for inclusion in the present analysis. Of these, 133 children aged 11-14 months were selected as the CG. Parents of five eligible CG children refused participation; thus, the remaining 128 guardians were interviewed and blood collection was scheduled for their children. In the IG, 193 children were enrolled by their primary health-care providers to receive MNP; thirty-nine were lost during follow-up, parents of eighteen declined 


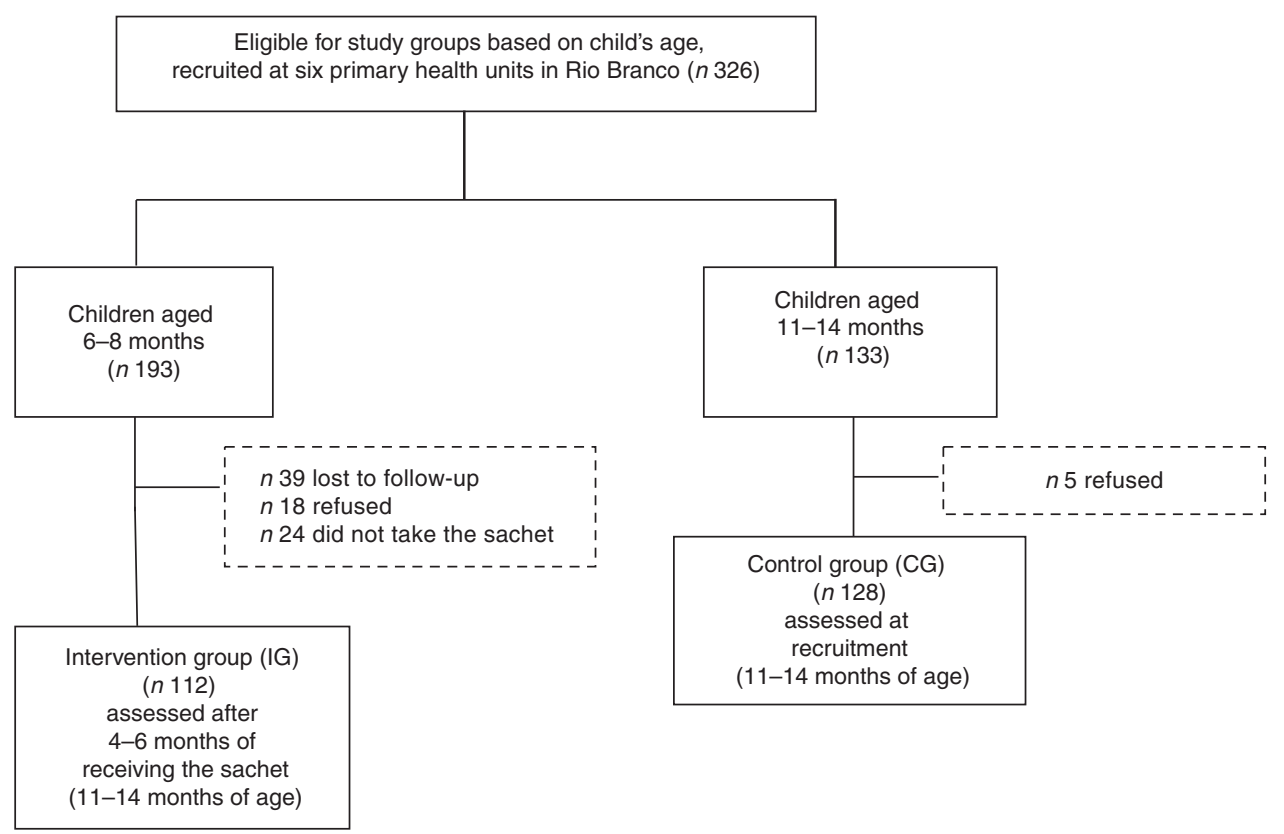

Fig. 1 Flowchart of study participants, Rio Branco, western Brazilian Amazon, 2012

participation at the recruitment and twenty-four did not take the sachets from the health professionals. The remaining 112 children were included in the analysis as the IG.

The sociodemographic characteristics of participants were similar in both study groups (Table 1 ). The median age of the mothers was 24 years; maternal education was 10 years for the CG and 11 years for the IG.

The prevalence of anaemia was similar in the study groups, but the prevalence of ID, IDA and VAD was significantly lower in the IG $(P<0.001)$ than the CG (65.2\% lower for ID, $73.0 \%$ lower for IDA and $74.8 \%$ lower for VAD; $P<0.001)$. The proportion of infants with vitamin A insufficiency and vitamin E insufficiency was $75.0 \%$ and $54.2 \%$ lower, respectively, in the IG than in the CG (Table 2). The mean Hb values were similar in the two study groups (CG: mean 117.0 (SD 10.0) g/l; IG: mean 118.4 (sD 10.6) $\mathrm{g} / \mathrm{l} ; P=0.325, t$ test). The prevalence ratio ( $95 \% \mathrm{CI})$ for anaemia, ID, IDA and VAD for IG $v$. CG children was $0.74(0.42,1.30), 0.34(0.24,0.49), 0.26$ $(0.10,0.68)$ and $0.25(0.09,0.64)$, respectively. The prevalence of stunting in the CG was $7 \cdot 3 \%$ (nine cases) while that in the IG was $0.9 \%$ (only one case). The mean HAZ value was higher in the IG than in the CC (CG: mean -0.26 (sD 1.27); IG: mean 0.26 (sD 1.10); $P<0.001, t$ test). The prevalence of VAD and ID in the IG in the absence of inflammation (serum C-reactive protein $<5 \mathrm{mg} / \mathrm{l}$ and $\alpha_{1}$-acid glycoprotein $<1 \mathrm{~g} / \mathrm{l}$ ) was significantly lower, $12.5 \%$ and $52.1 \%$, respectively (data not shown).

The intervention had no effect on the reported episodes of diarrhoea or fever in the prior $15 \mathrm{~d}$ or hospitalization in the prior 12 months. The frequencies of reported episodes of cough and wheezing were significantly higher in the CG than in the IG (Table 2). Multiple deficiencies (ID, VAD, vitamin $\mathrm{B}_{12}$ deficiency) were present in $3.9 \%$ of the children, all of them in the CG. Only $7 \%$ of the children had concurrent VAD and ID; none of these were in the IG. There were two cases of folate deficiency in the IG (1.9\%; data not shown).

The overall compliance with the recommended MNP supplementation (60 sachets) was $29.0 \%$, with a median (range) number of MNP sachets consumed per child of 45 (10-60). Approximately $69.5 \%$ of mothers reported that their child consumed $\geq 30$ sachets. Acceptability of the sachets by the child was reported as good or excellent by $65.5 \%$ of mothers/caregivers. The most frequent reasons for leftover sachets were rejection by the child (88.5\%) and mother/caregiver forgetting to offer the sachet or thinking it was unnecessary $(11.5 \%)$. The most common semi-solid food used for consumption of the sachet was mashed vegetables with eggs, meat or rice and beans (68.0\%), followed by porridge (20.6\%). Mashed fruits were used for sachet consumption in $11.3 \%$ of cases (data not shown).

The acceptability and adherence of the caregivers did not differ significantly based on the type of weaning food introduced; type of food also had no effect on biochemical indicators (data not shown). Although the type of food used for sachet administration had no influence on acceptability or adherence in children, it did have an effect on the frequency of anaemia. Children who received the sachet in porridge had a higher frequency of anaemia $(30 \cdot 0 \%, n$ 6) than those who used semi-solid food such as mashed vegetables with eggs, meat or rice and beans or fruits $(11.7 \%, n$ 9; $P=0.04$; data not shown). Among reported side-effects $(4.6 \%)$, diarrhoea was the most common $(41.7 \%)$. 
Table 1 Characteristics of the participants according to study group, Rio Branco, western Brazilian Amazon, 2012

\begin{tabular}{|c|c|c|c|c|c|}
\hline \multirow[b]{2}{*}{ Variable } & \multicolumn{2}{|c|}{$\begin{array}{l}\text { Control group, CG } \\
\quad(n 128)^{\star}\end{array}$} & \multicolumn{2}{|c|}{$\begin{array}{l}\text { Intervention group, IG } \\
(n 112)^{\star}\end{array}$} & \multirow[b]{2}{*}{$P \dagger$} \\
\hline & Mean & SD & Mean & SD & \\
\hline \multirow[t]{2}{*}{ Age (months) } & 12.91 & 0.89 & $12 \cdot 70$ & 1.01 & $0 \cdot 100$ \\
\hline & $n$ & $\%$ & $n$ & $\%$ & $P \neq$ \\
\hline Male & 71 & $55 \cdot 5$ & 53 & $47 \cdot 3$ & 0.208 \\
\hline Birth weight $(\mathrm{g})$ & & & & & 0.379 \\
\hline$<3500$ & 96 & $75 \cdot 6$ & 79 & 70.5 & \\
\hline$\geq 3500$ & 31 & $24 \cdot 4$ & 33 & 29.5 & \\
\hline Race/ethnicity & & & & & 0.259 \\
\hline Brown & 104 & $88 \cdot 1$ & 100 & $92 \cdot 6$ & \\
\hline Non-brown & 14 & 11.9 & 8 & 7.4 & \\
\hline Maternal education $<9$ years & 44 & $36 \cdot 4$ & 42 & 38.5 & 0.734 \\
\hline Paternal education $<9$ years & 50 & 43.5 & 44 & 41.9 & 0.814 \\
\hline \multicolumn{6}{|l|}{ Number of maternal children } \\
\hline 1 & 58 & $45 \cdot 3$ & 51 & $45 \cdot 5$ & 0.972 \\
\hline$\geq 2$ & 70 & 54.7 & 61 & 54.5 & \\
\hline Number of children $<5$ years in the household & & & & & 0.970 \\
\hline 1 & 90 & $70 \cdot 3$ & 79 & $70 \cdot 5$ & \\
\hline$\geq 2$ & 38 & 29.7 & 33 & 29.5 & \\
\hline Sanitary sewer & & & & & 0.102 \\
\hline Without connection & 55 & 44.4 & 38 & 33.9 & \\
\hline Connection to the public system & 69 & 55.7 & 74 & $66 \cdot 1$ & \\
\hline Adequate treatment of drinking water & 91 & $71 \cdot 1$ & 82 & 73.9 & 0.632 \\
\hline
\end{tabular}

${ }^{*}$ Totals differ from the total number of study children due to missing values for some variables.

†From Student's $t$ test.

†From Pearson's $X^{2}$ test.

Table 2 Prevalence of anaemia, morbidity and biochemical indicators according to study group, Rio Branco, western Brazilian Amazon, 2012

\begin{tabular}{|c|c|c|c|c|c|}
\hline \multirow[b]{2}{*}{ Variable } & \multicolumn{2}{|c|}{$\begin{array}{l}\text { Control group, CG } \\
(n \text { 128) }\end{array}$} & \multicolumn{2}{|c|}{$\begin{array}{l}\text { Intervention group, IG } \\
\qquad(n 112)^{*}\end{array}$} & \multirow[b]{2}{*}{$P+$} \\
\hline & $n$ & $\%$ & $n$ & $\%$ & \\
\hline Anaemiał & 26 & $20 \cdot 3$ & 17 & $15 \cdot 2$ & 0.301 \\
\hline ID§ & 92 & $72 \cdot 4$ & 27 & $25 \cdot 2$ & $<0.001$ \\
\hline IDAll & 22 & $17 \cdot 3$ & 5 & $4 \cdot \overline{7}$ & 0.003 \\
\hline VADI & 23 & 18.6 & 5 & 4.7 & $<0.001$ \\
\hline $\mathrm{VAl}^{\star *}$ & 65 & $52 \cdot 4$ & 14 & $13 \cdot 1$ & $<0.001$ \\
\hline VEIt† & 91 & 73.4 & 36 & $33 \cdot 6$ & $<0.001$ \\
\hline $\mathrm{VB}_{12} \mathrm{D} \neq \ddagger$ & 23 & 19.5 & 37 & 34.9 & 0.009 \\
\hline $\mathrm{CRP}>5 \mathrm{mg} / \mathrm{l}$ & 26 & $21 \cdot 0$ & 10 & 9.5 & 0.018 \\
\hline$A G P>1 \mathrm{~g} / \mathrm{l}$ & 51 & $41 \cdot 1$ & 28 & $26 \cdot 7$ & 0.022 \\
\hline $\begin{array}{l}\text { ID and } \mathrm{VB}_{12} \mathrm{D} \text {, combined } \\
\text { Morbidities in the last } 15 \mathrm{~d}\end{array}$ & 19 & $14 \cdot 8$ & 7 & $6 \cdot 3$ & 0.003 \\
\hline Diarrhoea & 35 & $27 \cdot 6$ & 28 & $25 \cdot 0$ & 0.654 \\
\hline Fever & 61 & $47 \cdot 7$ & 42 & 37.5 & 0.113 \\
\hline Cough & 88 & 68.8 & 42 & 37.5 & $<0.0001$ \\
\hline \multirow[t]{2}{*}{ Wheezing } & 59 & $46 \cdot 1$ & 10 & 8.9 & $<0.0001$ \\
\hline & Median & IQR & Median & IQR & $P \S \S$ \\
\hline$P F(\mu g / l)$ & $14 \cdot 98$ & $13 \cdot 53-16 \cdot 71$ & $33 \cdot 14$ & $28 \cdot 02-37 \cdot 15$ & $<0.001$ \\
\hline $\mathrm{sTfR}(\mathrm{mg} / \mathrm{l})$ & 9.99 & $8.86-10.91$ & $5 \cdot 23$ & $3.76-6 \cdot 11$ & $<0.001$ \\
\hline Serum $\beta$-carotene $(\mu \mathrm{mol} / \mathrm{l})$ & 0.22 & $0.18-0.26$ & 0.26 & $0.23-0.30$ & 0.014 \\
\hline Serum vitamin $E(\mu \mathrm{mol} / \mathrm{l})$ & $7 \cdot 00$ & $5 \cdot 51-8 \cdot 18$ & $14 \cdot 8$ & $12 \cdot 78-16 \cdot 01$ & $<0.001$ \\
\hline
\end{tabular}

ID, iron deficiency; IDA, iron-deficiency anaemia; VAD, vitamin A deficiency; VAI, vitamin A insufficiency; VEI, vitamin $E$ insufficiency; VB ${ }_{12} D$, vitamin $B_{12}$ deficiency; CRP, C-reactive protein; AGP, $a_{1}$-acid glycoprotein; PF, plasma ferritin; sTfR, soluble transferrin receptor; IQR, interquartile range.

*Totals differ from the total number of study children due to missing values.

†From Pearson $x^{2}$ test.

†Defined as $\mathrm{Hb}<110 \mathrm{~g} / \mathrm{l}$.

§lDefined as $\mathrm{PF}<12 \mu \mathrm{g} / \mathrm{ml}$ or $\mathrm{sTfR}>8.3 \mathrm{mg} / \mathrm{l}$.

$\| \mathrm{Hb}<110 \mathrm{~g} / \mathrm{l}$ with $\mathrm{PF}<12 \mu \mathrm{g} / \mathrm{l}$ or $\mathrm{sTfR}>8.3 \mathrm{mg} / \mathrm{l}$.

TDefined as serum retinol $<0.70 \mu \mathrm{mol} / \mathrm{l}$.

**Defined as serum retinol $<1.02 \mu \mathrm{mol} / \mathrm{l}$.

††Defined as serum vitamin $E<11.6 \mu \mathrm{mol} / \mathrm{l}$.

$\ddagger \ddagger$ Defined as serum vitamin $B_{12} \leq 150 \mathrm{pmol} / \mathrm{l}$.

$\S \S$ From Mann-Whitney $U$ test. 


\section{Discussion}

In the present study, home fortification with MNP daily for 2 months did not effectively reduce anaemia among young Amazonian children. However, the supplementation had a significant impact on ID and IDA in children in the IG, with improvements in Fe status, when compared with young children who attended at the routine health care without MNP. The observed ID reduction of $66 \%$ (prevalence ratio $=0 \cdot 34 ; 95 \% \mathrm{CI} 0 \cdot 24,0 \cdot 49$ ) was higher than that documented in a systematic Cochrane review $(51 \%)^{(11)}$.

Anaemia is considered the last stage of ID. Children who have ID without anaemia do not have sufficient Fe stores to mobilize if the body demands more Fe. Thus, if $\mathrm{Fe}$ is not provided, ID can progress to IDA, the most severe form of $\mathrm{ID}^{(26)}$. One explanation for the lack of impact in our study might be related to the higher mean $\mathrm{Hb}$ levels observed in both study groups compared with previous estimates. Because our study children were recruited at the primary health-care service, it is likely that the babies and their mothers received ferrous sulfate supplementation during their routine care at primary health-care units in the Amazon area ${ }^{(27)}$.

A recent review of the effects of food fortification on health and nutritional status reported that the impact of food fortification was greater in those with poorer nutritional status at baseline and that there was a greater haematological impact from food fortification with Fe and multiple micronutrient supplements in marginalized at-risk populations ${ }^{(5)}$. Thus, the effects of MNP may vary according to the underlying nutritional status of the target population, duration of the intervention, administration protocol and age group, as has been shown in other trials ${ }^{(15)}$.

Another important finding of our pragmatic trial was the substantial reduction in the prevalence of VAD among the IG children when compared with children attending the routine primary health care at the same age interval. This result corroborates the findings summarized in recent systematic reviews ${ }^{(13,14)}$ and those found in other studies $^{(28)}$, which reported that MNP affects vitamin A status. According to Salam et al. ${ }^{(14)}$, MNP reduced the prevalence of retinol deficiency by $21 \%$ (relative risk = 0.79; $95 \%$ CI 0.64, 0.98). In contrast, other studies have not found a significant effect of MNP on vitamin A status $^{(29)}$.

Mason et $a l .{ }^{(30)}$ proposed that vitamin A policies be reconsidered, because frequent regular vitamin A intake at physiological levels through food-based approaches, including fortification and regular low-dose supplementation, is highly effective at increasing serum retinol and reducing $\mathrm{VAD}$, whereas high-dose vitamin $\mathrm{A}$ at 6-month intervals does not reduce the prevalence of VAD. Although the biological mechanisms for the effect of vitamin A supplementation are unclear, the main argument for the low effectiveness of high-dose vitamin A in increasing serum retinol levels is based on studies conducted in the
Philippines ${ }^{(31)}$, which found that this increase is transitory, with retinol returning to pre-dose levels in less than 2 months. Three large recent studies on the effect of neonatal vitamin A supplementation ${ }^{(32-34)}$ reported that high-dose vitamin A did not have any benefit on survival in children under 6 months of age in Tanzania and Ghana. Only a study performed in India ${ }^{(34)}$ showed some evidence of survival benefit among infants at 6 months of age, probably because that population has high rates of infant mortality and widespread maternal VAD.

Previous studies have not found an association between MNP use and improvement in anthropometric outcomes $^{(28,35)}$ while others identified a small effect ${ }^{(15)}$. In our study, we observed a higher mean HAZ in the IG than in the CG, probably related to similar frequencies of recent episodes of diarrhoea and fever in the two groups as higher diarrhoea frequency could reduce the growth benefits of $\mathrm{MNP}^{(15)}$. Beyond that, there was a significantly lower frequency of cough and wheezing in the prior $15 \mathrm{~d}$ and a lower percentage of children with inflammation/ infection in the IG. It is noteworthy that the incidence of diarrhoea in our study was high among children in both groups ( 26\%). Young children in the Brazilian Amazon have been exposed to adverse living conditions for a long time. This chronic exposure can change the immediate responses of the immune system, such as C-reactive protein concentrations, to infection ${ }^{(36)}$.

Children's susceptibility to morbidity in the first years of life can have short-term effects on growth and nutrition ${ }^{(36)}$. Morbidity can directly affect nutrient concentrations through decreased appetite, whereas indirect effects are usually through alterations in immune activity. The effects of disease on nutritional status are influenced by both the duration and severity of illness ${ }^{(23)}$.

Although improvements in the quality of complementary feeding could not be adequately assessed in our study, serum concentrations of vitamin $\mathrm{E}$ and $\beta$-carotene were higher among the IG participants than in the CG. These micronutrients are considered good indicators of regular consumption of fruits and vegetables, which may indicate an improvement in the children's feeding patterns. Vitamin E insufficiency was $54.2 \%$ lower in the IG than in the CG, suggesting good adherence to the use of the sachets together with a range of different foods. Because the use of the sachets requires their addition to foods suitable for young children (such as mashed fruits and vegetables or rice and beans), this strategy offers an opportunity to promote healthy complementary feeding, further improving the benefits of fortification. Serum folate concentrations were similar in both study groups, with the low prevalence of folate deficiency probably related to mandatory fortification of flour in Brazil.

In the present study, MNP was well accepted by caregivers and children once its use and perceived beneficial effects on children's health were considered by mothers and health professionals. Acceptability rates for MNP have 
generally been above $83 \%$ in studies in developing countries, although rates are somewhat lower in studies performed in developed countries such as Canada $(60 \%)^{(37)}$. A systematic review of the effectiveness of MNP interventions found high acceptability with variable adherence $^{(12)}$. However, it is likely that increased knowledge and engagement of health professionals and caregivers concerning the use of MNP could have increased the adherence, resulting in a greater impact on health outcomes.

Previous studies have reported that lack of knowledge and experience among professionals and caregivers in the use of MNP limits its use ${ }^{(38)}$. Both adherence and acceptability can be increased with adjustments in the distribution model, such as providing better guidance to caregivers, integration with the actions already performed by the health-care team, regular monitoring of children through household visits by community health workers and MNP administration frequency. Equally important in the success of the intervention is that mothers have a strong understanding of the importance of vitamins and minerals for their children ${ }^{(39)}$.

Our study has some limitations. The study design did not allow randomization or blinding. The best study design for an effectiveness trial is a cluster-randomized controlled trial. However, ethical restrictions in our routine paediatric care did not allow collection of blood samples to screen infants at baseline as part of an alternative strategy to prevent anaemia. Thus, a pragmatic approach using a CG just before the intervention period was feasible in this setting. Despite these limitations, our results provide valuable information about MNP intervention through primary health care in the Brazilian Amazonian region.

\section{Conclusion}

In summary, this is the first pragmatic trial of MNP use in the Brazilian Amazon to be reported. In light of our findings, we propose that home fortification of complementary feeding with MNP is effective as a public health strategy for preventing and controlling $\mathrm{Fe}$ and vitamin A deficiencies in young children. This strategy may also contribute to improved child feeding practices, with potential benefits in reducing susceptibility to infection and, consequently, in improving health profiles. Our findings may provide better understanding and guide future development of MNP-effectiveness trials in Latin America countries. Large-scale studies measuring the impact of fortification on health outcomes such as morbidity are still needed, particularly studies that monitor children over an extended period of time.

\section{Acknowledgements}

Acknowledgements: The authors are profoundly grateful to all the children and their families who participated in the study, to the health professionals of Rio Branco and to the fieldwork research team for valuable assistance. Financial support: This work was supported by the Ministry of Health of Brazil with administrative and financial management by the National Council of Technological and Scientific Development (CNPq) (grant number 552747/2011-4). C.S.M.O. was supported by a $\mathrm{PhD}$ scholarship from Fundação de Amparo à Pesquisa do Acre (FAPAC). The views expressed on this paper do not necessarily reflect those of the Ministry of Health of Brazil. Neither of the organizations involved in supporting this work had a role in the analysis or interpretation of the data. Conflict of interest: None to declare. Authorship: C.S.M.O., P.S. and P.T.M. participated in fieldwork. C.S.M.O. conducted the data analysis and wrote the initial version of the manuscript. M.A.C. reviewed data analysis, interpretation and the manuscript writing. All authors have read and approved the final manuscript. Ethics of buman subject participation: This study was conducted according to the guidelines laid down in the Declaration of Helsinki and all procedures involving human subjects/patients were approved by the human ethical review board of the School of Public Health, University of São Paulo, Brazil. Written informed consent for participation was obtained from parents or guardians before enrolment. This study is part of a multicentre study registered at www.ensaio sclinicos.gov.br as RBR-5ktv6b.

\section{References}

1. World Health Organization (2001) Iron Deficiency Anaemia Assessment, Prevention and Control. A Guide for Programme Managers. Geneva: WHO.

2. Stevens GA, Finucane MM, De-Regil LM et al. (2013) Global, regional, and national trends in haemoglobin concentration and prevalence of total and severe anaemia in children and pregnant and non-pregnant women for 1995-2011: a systematic analysis of population-representative data. Lancet Glob Health 1, e16-e25.

3. World Health Organization (2009) Global Prevalence of Vitamin A Deficiency in Populations at Risk 1995-2005. WHO Global Database on Vitamin A Deficiency. Geneva: WHO.

4. World Health Organization (2008) Worldwide Prevalence of Anaemia 1993-2005. WHO Global Database on Anaemia. Geneva: WHO.

5. Das JK, Salam RA, Kumar R et al. (2013) Micronutrient fortification of food and its impact on woman and child health: a systematic review. Syst Rev 2, 67.

6. Arsenault JE, Yakes EA, Islam MM et al. (2013) Very low adequacy of micronutrient intakes by young children and women in rural Bangladesh is primarily explained by low food intake and limited diversity. J Nutr 143, 197-203.

7. Bailey RL, West KP Jr \& Black RE (2015) The epidemiology of global micronutrient deficiencies. Ann Nutr Metab 66, Suppl. 2, S22-S33.

8. Cembranel F, Dallazen C \& Gonzalez-Chica DA (2013) Effectiveness of ferrous sulfate supplementation in the prevention of anemia in children: a systematic literature review and meta-analysis. Cad Saude Publica 29, 1731-1751. 
9. Assunção MCF, Santos IS, Barros AJD et al. (2012) Flour fortification with iron has no impact on anaemia in urban Brazilian children. Public Health Nutr 15, 1796-1801.

10. Garcia MT, Granado FS \& Cardoso MA (2011) Complementary feeding and nutritional status of 6-24-month-old children in Acrelândia, Acre State, Western Brazilian Amazon. Cad Saude Publica 27, 305-316.

11. World Health Organization (2011) Use of Multiple Micronutrient Powders for Home Fortification of Foods Consumed by Infants and Children 6-23 Months of Age. Geneva: WHO.

12. De-Regil LM, Suchdev PS, Vist GE et al. (2011) Home fortification of foods with multiple micronutrient powders for health and nutrition in children under two years of age. Cochrane Database Syst Rev 9, CD008959.

13. Allen LH, Peerson JM \& Olney DK (2009) Provision of multiple rather than two or fewer micronutrients more effectively improves growth and other outcomes in micronutrient-deficient children and adults. J Nutr 139, 1022-1030.

14. Salam RA, MacPhail C \& Das JK (2013) Effectiveness of micronutrient powders (MNP) in women and children. BMC Public Health 13, 22.

15. Soofi S, Cousens S, Iqbal SP et al. (2013) Effect of provision of daily zinc and iron with several micronutrients on growth and morbidity among young children in Pakistan: a clusterrandomised trial. Lancet 382, 29-40.

16. Cardoso MA, Augusto RC, Bortolini GA et al. (2016) Effect of providing multiple micronutrients in powder through primary healthcare on anemia in young Brazilian children: a multicentre pragmatic controlled trial. PLoS One 11, e0151097.

17. Instituto Brasileiro de Geografia e Estatística (2010) Cidades. Resultados da amostra do Censo Demográfico 2010. http://cidades.ibge.gov.br/xtras/perfil.php?codmun=120040 (accessed May 2014).

18. Ministério da Saúde, Departamento de Atenção Básica (2014) Portal da Saúde. Histórico de Cobertura da Saúde da Família. Equipes da Saúde da Família. Fonte: MS/SAS/DAB e IBGE. http://dab.saude.gov.br/dab/historico_cobertura_ sf/historico_cobertura_sf_relatorio.php (accessed May 2014).

19. Hulley SB, Cummings SR, Browner WS et al. (2001) Designing Clinical Research, 2nd ed. Philadelphia, PA: Lippincott Williams \& Wilkins.

20. World Health Organization (1995) Physical Status: The Use and Interpretation of Anthropometry. Report of a WHO Expert Committee. WHO Technical Report Series no. 854. Geneva: WHO.

21. World Health Organization (2006) WHO child growth standards based on length/height, weight and age. Acta Paediatr Suppl 450, S76-S85.

22. Burger SE \& Pierre-Louis JN (2003) A Procedure to Estimate Accuracy and Reliability of HemoCue Measurements of Survey Workers. Washington, DC: International Life Sciences Institute.

23. Thurnham DI, McCabe LD, Haldar S et al. (2010) Adjusting plasma ferritin concentrations to remove the effects of subclinical inflammation in the assessment of iron deficiency: a meta-analysis. Am J Clin Nutr 92, 546-555.

24. World Health Organization (2008) Conclusions of a WHO Technical Consultation on folate and vitamin $\mathrm{B}_{12}$ deficiencies. Food Nutr Bull 29, Suppl. 2, S238-S244.

25. Gomes LF, Alves AF, Sevanian A et al. (2004) Role of $\beta_{2}$-glycoprotein I, LDL-, and antioxidant levels in hypercholesterolemic elderly subjects. Antioxid Redox Signal 6, 237-244.

26. Abdullah K, Thorpe KE, Mamak E et al. (2015) Optimizing early child development for young children with nonanemic iron deficiency in the primary care practice setting (OptEC): study protocol for a randomized controlled trial. Trials 16, 132.
27. Cardoso LSM, Mendes LL \& Velasquez-Melendez G (2013) Antenatal care differences in Brazilian urban and rural areas: a cross-sectional population-based study. Rev Min Enferm 17, 85-92.

28. Suchdev PS, Ruth LJ, Woodruff BA et al. (2012) Selling Sprinkles micronutrient powder reduces anemia, iron deficiency, and vitamin A deficiency in young children in Western Kenya: a cluster-randomized controlled trial. Am J Clin Nutr 95, 1223-1230.

29. Serdula MK, Lundeen E, Nichols EK et al. (2013) Effects of a large-scale micronutrient powder and young child feeding education program on the micronutrient status of children 6-24 months of age in the Kyrgyz Republic. Eur J Clin Nutr 67, 703-707.

30. Mason J, Greiner T, Shrimpton R et al. (2014) Vitamin A policies need rethinking. Int J Epidemiol 10, 1-10.

31. Pedro MR, Madriaga JR, Barba CV et al. (2004) The national vitamin A supplementation program and subclinical vitamin A deficiency among preschool children in the Philippines. Food Nutr Bull 25, 319-329.

32. Masanja H, Smith ER, Muhihi A et al.; Neovita Tanzania Study Group (2015) Effect of neonatal vitamin A supplementation on mortality in infants in Tanzania: a randomised, double-blind, placebo-controlled trial. Lancet 385, 1324-1332.

33. Edmond KM, Newton S, Shannon C et al. (2015) Effect of early neonatal vitamin A supplementation on mortality during infancy in Ghana (Neovita): a randomised, doubleblind, placebo-controlled trial. Lancet 385, 1315-1323.

34. Mazumder S, Taneja S, Bhatia K et al.; Neovita India Study Group (2015) Efficacy of early neonatal supplementation with vitamin A to reduce mortality in infancy in Haryana, India: a randomised, double-blind, placebo controlled trial. Lancet 385, 1333-1342.

35. Kounnavong S, Sunahara T, Mascie-Taylor CG et al. (2011) Effect of daily versus weekly home fortification with multiple micronutrient powder on haemoglobin concentration of young children in a rural area, Lao People's Democratic Republic: a randomised trial. Nutr J 10, 129.

36. Dewey KG \& Mayers DR (2011) Early child growth: how do nutrition and infection interact? Matern Child Nutr $\mathbf{7}$, 129-142.

37. Dewey KG, Yang Z \& Boy E (2009) Systematic review and meta-analysis of home fortification of complementary foods. Matern Child Nutr 5, 283-321.

38. Jefferds ME, Ogange L, Owuor M et al. (2010) Formative research exploring acceptability, utilization, and promotion in order to develop a micronutrient powder (Sprinkles) intervention among Luo families in western Kenya. Food Nutr Bull 31, 2 Suppl., S179-S185.

39. Geltman PL, Hironaka LK, Mehta SD et al. (2009) Iron supplementation of low-income infants: a randomized clinical trial of adherence with ferrous fumarate sprinkles versus ferrous sulfate drops. J Pediatr 154, 738-743.

\section{Appendix}

\section{The ENFAC Working Group}

Marly Augusto Cardoso, Rosângela Aparecida Augusto, Fernanda Cobayashi (Departament of Nutrition, University of São Paulo, São Paulo, Brazil); Cristieli Sérgio de Menezes Oliveira, Pascoal Torres Muniz (Centre of Health Sciences and Sport, Federal University of Acre, Rio Branco, Brazil); Maria Claret C.M. Hadler, Maria do Rosário G. Peixoto (School of Nutrition, Federal University of Goiás, Goiânia, Brazil); Pedro Israel C. Lira, Leopoldina 
Augusta S. Sequeira (Department of Nutrition, Universidade Federal de Pernambuco, Recife, Brazil); Márcia Maria Tavares Machado (Department of Preventive Medicine, Federal University of Ceará, Fortaleza, Brazil); Márcia Regina Vitolo, Daniela Cardoso Tietzmann
(Universidade Federal de Ciências da Saúde de Porto Alegre, Porto Alegre, Brazil); Patrícia Constante Jaime, Eduardo Augusto Fernandes Nilson, Gisele Ane Bortolini, Sara Araújo da Silva (Coordenação Geral de Alimentação e Nutrição, Ministry of Health, Brasília, Brazil). 